\title{
Association of KCNQ1, KCNE1, KCNH2 and SCN5A polymorphisms with QTc interval length in a healthy population
}

\author{
Laetitia Gouas ${ }^{1}$, Viviane Nicaud ${ }^{2}$, Myriam Berthet ${ }^{1}$, Anne Forhan ${ }^{3}$, Laurence Tiret ${ }^{2}$, \\ Beverley Balkau ${ }^{3}$, Pascale Guicheney ${ }^{* 1}$ and the D.E.S.I.R. Study Group
}

\author{
${ }^{1}$ INSERM U582, Institut de Myologie, IFR 14, UPMC, Groupe Hospitalier Pitié-Salpêtrière, Paris, France; ${ }^{2}$ INSERM \\ U525, IFR 14, UPMC, Groupe Hospitalier Pitié-Salpêtrière, Paris, France; ${ }^{3}$ INSERM U258, IFR 69, Villejuif, France
}

The QT interval (QT) reflects cardiac ventricular repolarization and varies according to various known factors such as heart rate, gender and age. Nevertheless, a high intrasubject stability of the QT-RR pattern also suggests that a genetic component contributes to individual QT length. To determine whether single nucleotide polymorphisms (SNPs) in genes encoding cardiac ion channels were associated with the heartrate corrected QT (QTc) length, we analyzed two groups of 200 subjects presenting the shortest and the longest QTc from a cohort of 2008 healthy subjects. A total of 17 polymorphisms were genotyped; they were all in the Hardy-Weinberg equilibrium in both groups. Neither allele nor haplotype frequencies of the 10 KCNQ1 SNPs showed a significant difference between the two groups. In contrast, KCNH2 $2690 \mathrm{C}$ (K897T) and SCN5A 5457 T (D1819D) minor alleles were significantly more frequent in the group with the shortest QTc interval, whereas KCNE1 253 A (D85N), SCN5A 1673 G (H558R) and 1141-3 A minor alleles were significantly more frequent in the group with the longest QTc interval. Interestingly, an interaction was also found between the $K C N H 22690$ A $>$ C SNP and the $K C N Q 12031+932$ A $>$ G SNP suggesting that the effect of the $K C N H 22690 \mathrm{C}$ allele on QTc length may occur within a particular genetic background. This suggests that genetic determinants located in KCNQ1, KCNE1, KCNH2 and SCN5A influence QTc length in healthy individuals and may represent risk factors for arrhythmias or cardiac sudden death in patients with cardiovascular diseases.

European Journal of Human Genetics (2005) 13, 1213-1222. doi:10.1038/sj.ejhg.5201489;

published online 31 August 2005

Keywords: gene polymorphisms; ion channels; QT interval

Introduction

The QT interval (QT), measured on the electrocardiogram (ECG), reflects cardiac ventricular repolarization. In healthy populations, its length varies widely and several

*Correspondence: Dr P Guicheney, INSERM U582, Groupe Hospitalier Pitié-Salpêtrière, 47 boulevard de I'Hôpital, 75651 Paris cedex 13, France. Tel: + 331421657 50; Fax: + 331421657 00;

E-mail: p.guicheney@myologie.chups.jussieu.fr

Received 22 February 2005; revised 9 May 2005; accepted 13 July 2005; published online 31 August 2005 factors such as heart rate, gender and age exert an influence on the QT length. ${ }^{1,2}$ Indeed, women present relative QT prolongation compared with men $^{3,4}$ and QT shortens in men after puberty. ${ }^{2}$ Whereas there exists a substantial interindividual variability of the QT-RR relationship, which represents the relationship between QT duration and heart rate, a high intraindividual stability of the QT-RR pattern has been shown, suggesting that a genetic component might partly determine individual QT length. ${ }^{5,6}$ Indeed, Busjahn et $a l^{7}$ have shown a significant linkage in dizygotic twins between heart rate-corrected QT interval (QTc) and 
two loci harboring genes known to cause the long QT syndrome (LQTS).

Ventricular action potential (AP) is under the joint control of the depolarizing $\mathrm{Na}^{+}\left(I_{\mathrm{Na}}\right)$ and the repolarizing slow $\left(I_{\mathrm{Ks}}\right)$ and rapid $\left(I_{\mathrm{Kr}}\right) \mathrm{K}^{+}$-delayed rectifier currents. The activity and expression levels of each of these current-underlying channels establish a subtle equilibrium between depolarizing and repolarizing currents determining the AP duration in each individual. Thus, it would not be surprising that polymorphisms in the genes coding for these channels may influence this equilibrium even by weak effects on activity and/or expression level of channels subunits.

The cardiac $I_{\mathrm{Na}}$ current is underlined by the $\alpha \mathrm{Na}_{\mathrm{v}} 1.5$ subunit channel encoded by the SCN5A gene. As for the $\mathrm{K}^{+}$-delayed rectifier current, the $I_{\mathrm{Ks}}$ current is elicited by the $\alpha$ KvLQT1 and $\beta$ minK subunits encoded by the KCNQ1 and KCNE1 genes, respectively, and the $I_{\mathrm{Kr}}$ current by the $\alpha$ HERG and $\beta$ Mirp1 subunits encoded, respectively, by the KCNH2 and KCNE2 genes. ${ }^{8-11}$

Mutations in these ion channel subunits are responsible for the LQTS, where a decrease in outward $\mathrm{K}^{+}$current or an increase in inward $\mathrm{Na}^{+}$current results in a prolongation of the AP. This prolongation, leading to a prolonged QT interval on baseline ECG, renders patients at high risk of developing torsades de pointes or ventricular fibrillation leading to syncope or sudden death. However, more recently, mutations in $K C N H 2$ and $K C N Q 1$, leading to an increase in outward $\mathrm{K}^{+}$current, have also been linked to the short QT syndrome (SQTS). In SQTS, a drastic decrease of the QTc interval is also linked to life-threatening arrhythmias and sudden death. ${ }^{12,13}$

It is now widely recognized that penetrance of these monogenic arrhythmias is highly variable. In other words, among individuals carrying the same causative mutation within a specific affected kindred, some express a clinical phenotype whereas others do not manifest a phenotype. ${ }^{14}$ Variability elsewhere in the genome, such as polymorphisms in the same disease-causing gene or in other genes, might contribute to this variable penetrance as well as to the appearance of a clinical phenotype. For example, the SCN5A H558R variant which is a common polymorphism in the American population, ${ }^{15}$ was shown to mitigate the in vitro effects of a nearby mutation on the $\mathrm{Na}^{+}$channel function $^{16}$ whereas coinheritance of the SCN5A D $1275 \mathrm{~N}$ variant with a rare haplotype in the $C x 40$ gene was associated with an atrial standstill phenotype in a kindred. ${ }^{17}$

It has also been shown that not only rare mutations ${ }^{11,15,18}$ but also polymorphisms in KCNE1, KCNE2 and $S C N 5 A$ could represent risk factors for drug-induced arrhythmias. $^{18-20}$

Some polymorphisms have already been reported to be associated with the QTc length. The K897T amino-acid variant of $\mathrm{KCNH} 2$ was associated with the length of QT interval in Finnish LQT1 patients. ${ }^{21}$ Bezzina et al ${ }^{22}$ reported in healthy women, that homozygote carriers for the T897 allele had shorter QTc than homozygote for the K897 allele. Very recently, single nucleotide polymorphisms (SNPs) in other ion channel subunits were also associated with the QTc length in healthy individuals. ${ }^{23}$

Given the major role of cardiac sodium and potassium channels in ventricular repolarization, we investigated the potential association of $10 K C N Q 1$, two KCNE1, four SCN5A polymorphisms and the KCNH2 K897T variant with the QTc length in a healthy French population. We also tested whether these SNPs might interact to influence on the QTc duration.

\section{Material and methods Study population}

Participants of the Data from an Epidemiological Study on the Insulin Resistance syndrome (D.E.S.I.R.) cohort gave informed consent to the clinical and genetic study, which was approved by an ethics committee. The investigations conform to the principles outlined in the Declaration of Helsinki.

\section{The D.E.S.I.R. study}

The study subjects were selected from the D.E.S.I.R. cohort, which included French men and women aged 30-64 years. Participants were volunteers who agreed to be followed for 9 years and to have a clinical examination every 3 years. This study involved 10 health examination centers in France. ${ }^{24,25}$

The first examination took place in 1994 (D0) and the second in 1997 (D3). Blood pressure was measured after at least $5 \mathrm{~min}$ rest and venous blood samples were collected to determine glucose, triglyceride and HDL-cholesterol concentrations. Disease history (diabetes, hypertension, cardiovascular disease, etc), medical treatment, physical activity, alcohol and tobacco consumption were collected for each subject.

Subjects underwent a 12-lead resting ECG. QT intervals were measured in lead II (ms) by Cardionics ${ }^{\circledR}$ software and corrected for heart rate by use of the Fridericia formula (QTc) ${ }^{26}$ Subjects with an ECG recording at D0 and D3 ( $n=3478$ ) form the basis of the study. We excluded the subjects $(n=1399)$ with known or detected cardiac pathology, diabetes (defined by use of treatment or a fasting plasma glucose level $(\geq 7.0 \mathrm{mmol} / \mathrm{l}))$, treated or untreated high blood pressure as well as the subjects taking medication known to prolong the QT interval such as neuroleptics, antiarrhythmics or antihistaminics, at D0 and D3. Subjects with a difference $\geq 30 \mathrm{~ms}$ in QTc between the two examinations were also excluded $(n=71)$.

The distribution of the mean QTc values (averaged on measures at D0 and D3) of the remaining healthy subjects ( $n=2008$ ) is shown in the Supplementary Figure 1 . Mean QTc values were adjusted for age, separately in men and women, and the residuals were used to select the 100 men 
and 100 women with the shortest QTc, and 100 men and 100 women with the longest QTc.

In a preliminary study, the KCNQ1 exons had been sequenced in the 50 men and 50 women with the longest QTc, and two new KCNQ1 mutations had been identified (Y148X, $\Delta$ S276). ${ }^{27}$ The two carriers of these mutations whose QTc interval prolongation was assumed to be due to these mutations were excluded from the study.

\section{Genetic analysis}

Genomic DNA amplification Genomic DNA was prepared from peripheral blood lymphocytes by standard procedures. Previously designed primers were used to amplify the KCNQ1 exons by PCR. ${ }^{28}$ Primers used to amplify KCNQ1 3'UTR region, KCNE1, SCN5A and KCNH2 DNA sequences are given on the European Journal of Human Genetics website.

Sequence analysis DNA sequences containing the KCNQ1 2031+479 G>A, 2031+875 A>G and $2031+932 \mathrm{~A}>\mathrm{G}$, the KCNE1 $112 \mathrm{G}>\mathrm{A}$ and $253 \mathrm{G}>\mathrm{A}$, and the $S C N 5 A-92 \mathrm{C}>\mathrm{A}$ polymorphisms were amplified by PCR using a GeneAmp ThermoCycler 9700 (Applied Biosystems). The PCR products were cleaned up using Bio$\mathrm{Gel}^{\circledR} \mathrm{P}-100 \mathrm{Gel}$ (Bio-Rad) spin columns in a MultiScreen ${ }^{\mathrm{TM}}$ 96-well filter plate (Milipore). The sequencing reactions were performed by the dideoxynucleotide chain termination method with fluorescent dideoxynucleotides according to the dGTP Big Dye ${ }^{\circledR}$ Terminator v3.0 protocol, then cleaned up using Sephadex ${ }^{\mathrm{TM}}$ G50 Superfine (Amersham Biosciences) spin columns in a MultiScreen ${ }^{\text {TM }}$ 96-well filter plate. The reactions were run on an ABI 377 (Applied Biosystems).

Fluorescent-SSCP (F-SSCP) DNA sequences containing the KCNQ1 $477+80$ insGG, $1514+46 \mathrm{~A}>\mathrm{G}, 1590+14$ $\mathrm{T}>\mathrm{C}, 1638 \mathrm{G}>\mathrm{A}, 1732+43 \mathrm{~T}>\mathrm{C}$ and $1794+32 \mathrm{G}>\mathrm{T}$ were amplified by PCR using ThermoCycler ${ }^{\mathrm{TM}} 9700$ (Applied Biosystem). PCR was carried out using fluorescent-dyelabeled sense and antisense primers specific for the DNA region of interest $\left(6 \mathrm{FAM}^{\mathrm{TM}}, \mathrm{HEX}^{\mathrm{TM}}\right)$. In all, $0.5-2 \mu \mathrm{l}$ of PCR amplicons were mixed to a denaturing buffer $(50 \%$ formamide, $25 \mu \mathrm{g}$ dextran blue $(50 \mathrm{mg} / \mathrm{ml}), 2.5 \mathrm{~mm}$ EDTA $(25 \mathrm{mM}))$ and to a DNA molecular weight standard (GENESCAN-500 Rox, Applied Biosystem). Samples were then denatured $5 \mathrm{~min}$ at $94^{\circ} \mathrm{C}$ and quenched on ice. In all, $1 \mu \mathrm{l}$ of samples was applied to a nondenaturing gel (MDE $0.5 \mathrm{X}, \mathrm{MGDA})$ and electrophoresed on the ABI 377 system. The mobility of F-SSCP fragments was measured relative to ROX size standard by use of Genescan 3.1.2 software (Applied Biosystems).

Fluorescence resonance energy transfer and probe melting curves The KCNQ1 $1986 \mathrm{C}>\mathrm{T}$ and $2031+875 \mathrm{~A}>\mathrm{G}$ ( $n=400$ and 200, respectively), the KCNH2 $2690 \mathrm{~A}>\mathrm{C}$ and the SCN5A $1673 \mathrm{~A}>\mathrm{G}, 5457 \mathrm{C}>\mathrm{T}$ and 1141-3 C>A polymorphisms were analyzed by Fluorescence Resonance Energy Transfer within a LightCycler (Roche Diagnostics). In all, $40 \mathrm{ng}$ of sample DNA was used to perform a $25 \mu \mathrm{lPCR}$ reaction containing the detection probe and the anchor probe for the KCNQ1 $1986 \mathrm{C}>\mathrm{T}, K C N H 22690 \mathrm{C}>\mathrm{A}$, SCN5A $1673 \mathrm{~A}>\mathrm{G}, 5457 \mathrm{C}>\mathrm{T}$ and 1141-3 C>A polymorphisms in a GeneAmp ThermoCycler 9700 system (Perkin Elmer). PCR amplicons were then loaded into glass capillary cuvettes (Roche Diagnostics). After an initial denaturation step at $95^{\circ} \mathrm{C}$ for $30 \mathrm{~s}$, a melting curve was recorded by cooling the reaction mixture to $40^{\circ} \mathrm{C}$ at $20^{\circ} \mathrm{C} / \mathrm{s}$, holding it at $40^{\circ} \mathrm{C}$ for $120 \mathrm{~s}$, and then slowly heating it to $85^{\circ} \mathrm{C}$ at $0.1^{\circ} \mathrm{C} / \mathrm{s}$. Fluorescence was measured continuously during the slow temperature ramp to monitor the dissociation of the fluorescein-labeled detection probe. For the KCNQ1 $2031+875 \mathrm{~A}>\mathrm{G}, 40 \mathrm{ng}$ of sample DNA was used to do PCR reactions in the LightCycler in a reaction volume of $20 \mu \mathrm{l}$ with $0.4 \mu \mathrm{mol} / \mathrm{l}$ of each primer, $0.06 \mu \mathrm{mol} / 1$ anchor and detection probes, $3 \mathrm{mmol} / \mathrm{l} \mathrm{MgCl}_{2}$ and $2 \mu \mathrm{l}$ of the Master Mix Hybridyzation Probes (Roche Diagnostics). After an initial denaturation step at $95^{\circ} \mathrm{C}$ for $30 \mathrm{~s}$, amplification was performed using 40 cycles of denaturation $\left(95^{\circ} \mathrm{C}\right.$ for $\left.3 \mathrm{~s}\right)$, annealing $\left(55^{\circ} \mathrm{C}\right.$ for $\left.10 \mathrm{~s}\right)$ and extension $\left(72^{\circ} \mathrm{C}\right.$ for $\left.15 \mathrm{~s}\right)$. The temperature transition rates were programmed at $20^{\circ} \mathrm{C} / \mathrm{s}$ from denaturation to annealing, $5^{\circ} \mathrm{C} / \mathrm{s}$ from annealing to extension, and $20^{\circ} \mathrm{C} / \mathrm{s}$ from extension to denaturation. After amplification was complete, a final melting curve was recorded as described above.

\section{Statistical analysis}

The difference between the mean QTc value between the two groups for men and women was assessed by a MannWhitney Rank Sum test (SygmaStat). Deviation from the Hardy-Weinberg equilibrium was tested by $\chi^{2}$ analysis with 1 degree of freedom in the shortest and longest QTc groups separately. Pairwise linkage disequilibrium (LD) coefficients between polymorphisms were estimated by log-linear model analysis ${ }^{29}$ and the extent of disequilibrium was expressed in terms of $D^{\prime}=D / D_{\max }$ or $-D / D_{\min }$. Allele frequencies were estimated from genotype frequencies by gene counting. The study was analyzed as a case/ control study comparing the longest and the shortest QTC groups. Genotype and allele frequencies were compared between the two groups by $\chi^{2}$ test. Homogeneity of the association according to gender was systematically tested and since there was no heterogeneity for any of the polymorphisms, men and women were pooled for analysis. The odds ratio (OR) [95\% CI] for longest QTc associated with genotype was estimated from logistic regression analysis adjusted for age and sex. A $P$-value $<0.05$ was considered statistically significant. All computations were carried out with the SAS software (SAS Institute, Cary, NC, USA). 
To analyze simultaneously all polymorphisms of a gene, haplotype analyses were performed by use of a maximum likelihood model ${ }^{30}$ implemented in the THESIAS program (http://www.genecanvas.org). In these analyses, the haplotype combining the most frequent alleles at each locus was used as the reference.

We applied the detection of informative combined effect (DICE) method ${ }^{31}{ }^{-}$to investigate high-order interactions between polymorphisms of the different genes on the phenotype. Briefly, the DICE algorithm explores in an automated way all combinations of polymorphisms acting either in an additive or in an interactive way (three-order interaction at maximum). Models of increasing complexity are successively fitted to data and the difference $\Delta_{\mathrm{s}}$ of the Akaike's information criterion between models indicates whether the fit is substantially improved, that is, when $\Delta_{\mathrm{s}}$ exceeds a predetermined threshold. The algorithm stops when no model leads to a $\Delta_{\mathrm{s}}$ higher than the fixed threshold. Given the large number of polymorphisms investigated, a rather stringent threshold was chosen $\left(\Delta_{\mathrm{s}}>6\right)$. In this analysis, a dominant coding scheme for polymorphisms was adopted (frequent homozygotes opposed to carriers of the minor allele).

\section{Results}

Baseline characteristics of the two groups are presented in Table 1.

\section{KCNQ1 polymorphisms}

In a preliminary study, the KCNQ1 exons had been sequenced in the 100 subjects with the longest QTc intervals and 18 SNPs were found. In Table 2 we report the SNP position, the SNP Identity (ID) from public databases, when available, and their allele frequencies. According to arrhythmia literature, the National Center for

Table 1 Mean $( \pm S D)$ ages, heart rates and QTc intervals in men and women of the shortest and longest QTc groups

\begin{tabular}{|c|c|c|c|c|}
\hline & \multicolumn{2}{|c|}{ Shortest QTC group } & \multicolumn{2}{|c|}{ Longest QTC group } \\
\hline & $\begin{array}{c}\text { Men } \\
N=100\end{array}$ & $\begin{array}{l}\text { Women } \\
N=100\end{array}$ & $\begin{array}{c}\text { Men } \\
N=99\end{array}$ & $\begin{array}{c}\text { Women } \\
N=99\end{array}$ \\
\hline $\begin{array}{l}\text { Age } \\
\text { Heart rate (beats/min) } \\
\text { QTc interval (ms) } \\
\text { QTc range }\end{array}$ & $\begin{array}{c}45 \pm 10 \\
66 \pm 10 \\
353 \pm 6 \\
333-363\end{array}$ & $\begin{array}{c}46 \pm 10 \\
69 \pm 11 \\
357 \pm 6 \\
336-365\end{array}$ & $\begin{array}{c}44 \pm 9 \\
61 \pm 10 \\
406 \pm 9 \\
394-433\end{array}$ & $\begin{array}{c}46 \pm 10 \\
67 \pm 10 \\
410 \pm 7 \\
400-432\end{array}$ \\
\hline
\end{tabular}

Mean QTc interval values are statistically different between the groups with the shortest and the longest QTc intervals for men and women $(P<0.001)$.

Table 2 KCNQ1 variants identified in the D.E.S.I.R. population

\begin{tabular}{|c|c|c|c|c|c|c|}
\hline Nucleotide change & Region & $\begin{array}{l}\text { Coding } \\
\text { polymorphism }\end{array}$ & $\begin{array}{l}\text { Frequency of } \\
\text { minor allele }\end{array}$ & $\begin{array}{l}\text { Number of } \\
\text { chromosomes } \\
\text { examined }\end{array}$ & Previous reports & SNP ID \\
\hline $459 \mathrm{G}>\mathrm{T}$ & Exon 1 & T153T & 0.00375 & 800 & \multirow{9}{*}{ Jongbloed et al (2002) } & \multirow{8}{*}{ rs12786951 } \\
\hline $477+20 A>C$ & Intron 1 & & 0.00125 & 800 & & \\
\hline $477+80$ insGG $^{a}$ & Intron 1 & & 0.31 & 800 & & \\
\hline $780+77 A>G$ & Intron 4 & & 0.27 & 200 & & \\
\hline $811 \mathrm{C}>\mathrm{T}$ & Exon 5 & L271L & 0.005 & 200 & & \\
\hline $918+13 \mathrm{C}>\mathrm{T}$ & Intron 5 & & 0.005 & 200 & & \\
\hline $984 \mathrm{C}>\mathrm{T}$ & Exon 6 & |328| & 0.005 & 200 & & \\
\hline $1514+7 \mathrm{G}>\mathrm{T}$ & Intron 10 & & 0.005 & 200 & & \\
\hline $1514+14 G>T$ & Intron 10 & & 0.005 & 200 & & \multirow{4}{*}{$\begin{array}{l}\text { rs760419 } \\
\text { rs11024034 } \\
\text { rs } 1057128\end{array}$} \\
\hline $1514+46 A>C^{a}$ & Intron 10 & & 0.42 & 800 & \multirow{5}{*}{$\begin{array}{l}\text { Aydin et al (2004) } \\
\text { Jongbloed et al (2002) } \\
\text { Lee et al (1997); Iwasa et al } \\
\text { (2000); Jongbloed et al (2002) } \\
\text { Iwasa et al (2000); Jongbloed } \\
\text { et al (2002) }\end{array}$} & \\
\hline $1590+14 \mathrm{~T}>\mathrm{C}^{\mathrm{a}}$ & Intron 11 & & 0.08 & 800 & & \\
\hline $1638 G>A^{a}$ & Exon 12 & S546S & 0.21 & 800 & & \\
\hline $1732+43 \mathrm{~T}>\mathrm{C}^{\mathrm{a}}$ & Intron 13 & & 0.26 & 800 & & rs81204 \\
\hline $1794+32 \mathrm{G}>\mathrm{T}^{\mathrm{a}}$ & Intron 14 & & 0.05 & 800 & & \\
\hline $1986 \mathrm{C}>\mathrm{T}^{\mathrm{a}}$ & Exon 15 & Y $662 Y$ & 0.25 & 800 & Jongbloed et al (2002) & rs11601907 \\
\hline $2031+$ & 3'UTR & & 0.06 & 800 & & \\
\hline $2031+875 \mathrm{~A}>\mathrm{G}^{\mathrm{a}}$ & 3'UTR & & 0.3 & 800 & & rs2519184 \\
\hline $2031+932 \mathrm{~A}>\mathrm{C}^{\mathrm{a}}$ & 3'UTR & & 0.32 & 800 & & rs 10798 \\
\hline
\end{tabular}

Nucleotide numbering starts from the ATG start codon (Genbank accession AF000571).

apolymorphisms analyzed in this study. 
Biotechnology Information (http://www.ncbi.nlm.nih. gov) and the inherited arrhythmias databases (http:// pc4.fsm.it:81/cardmoc/), eight of the 18 SNPs were unknown. Six SNPs were rare $(<0.01)$ and consisted in a synonymous G-to-T substitution at position 459 in exon 1 (T153T), a A-to-G substitution at position $477+21$ in intron 1, a C-to-T substitution at position $918+13$ in intron 5, a synonymous C-to-T substitution at position 984 in exon 6 (I328I), a G-to-T substitution at position $1514+7$ and $1514+14$ in intron 10 . Two polymorphisms were more frequent $(>0.01)$ and consisted in a GG insertion/ deletion at position $477+80$ of intron 1 and a G-to-A substitution at position $2031+479$ in the $3^{\prime}$ UTR part.

After exclusion of rare polymorphisms, two synonymous polymorphisms in the coding region of KCNQ1, S546S and Y662Y (1638 G > A and $1986 \mathrm{C}>\mathrm{T}$, respectively), five SNPs in intronic sequences $(477+80$ insGG in intron 1 , $1514+46 \mathrm{~A}>\mathrm{G}$ in intron $10,1590+14 \mathrm{~T}>\mathrm{C}$ in intron $11,1732+43 \mathrm{~T}>\mathrm{C}$ in intron $13,1794+32 \mathrm{G}>\mathrm{T}$ in intron 14) and three SNPs in the $3^{\prime} \mathrm{UTR}$ part $(2031+479 \mathrm{G}>\mathrm{A}$, $2031+875 \mathrm{~A}>\mathrm{G}$ and $2031+932 \mathrm{~A}>\mathrm{G}$ ) of the KCNQ1 gene were studied.

There was no deviation from the Hardy-Weinberg equilibrium for any of the polymorphisms considered. The frequency of the minor allele ranged from 0.05 to 0.42 (Table 2). The three polymorphisms in the $3^{\prime}$ end of the gene and the polymorphism $1986 \mathrm{C}>\mathrm{T}$ in exon 15 were in strong LD with each other (absolute pairwise LD coefficients ranging from 0.68 to 0.90). Moreover, the $2031+875 \mathrm{~A}>\mathrm{G}$ and $2031+932 \mathrm{~A}>\mathrm{G}$ SNPs were in nearly complete association (only $9.8 \%$ of the subjects were recombinants). Conversely, the polymorphisms located upstream from exon 15 exhibited very weak LD. The detailed LD coefficients can be found in the web supplement (Table A, web supplement).

None of the KCNQ1 polymorphisms exhibited significant difference of genotype or allele frequencies between the groups with the shortest and the longest QTc intervals (data not shown). Given the strong LD between polymorphisms located in exon 15 and $3^{\prime}$ UTR, a haplotype analysis of these four polymorphisms was performed. They generated six common haplotypes, which were similarly distributed between the two groups.

\section{KCNE1 polymorphisms}

The known SNPs, $112 \mathrm{G}>\mathrm{A}$ and $253 \mathrm{G}>\mathrm{A}$, leading to the amino-acid changes G38S and D85N, respectively, were analyzed. Genotype frequencies did not deviate from the Hardy-Weinberg equilibrium in either group. The two polymorphisms were in weak $\operatorname{LD}\left(D^{\prime}=-0.46\right)$ (Table $\mathrm{B}$, web supplement).

Allele and genotype frequencies of the $112 \mathrm{G}>\mathrm{A}$ SNP (G38S) did not differ significantly between the two groups (Table 3). By contrast, the A allele of the $253 \mathrm{G}>\mathrm{A}$ SNP (D85N) was significantly more frequent in the longest than
Table 3 Frequency of KCNE1 gene polymorphisms in the shortest and longest QTC groups and odds ratio $(95 \% \mathrm{Cl})$ for longest QTC associated with genotype

\begin{tabular}{lcc}
\hline & \multicolumn{2}{c}{ QTC } \\
Polymorphism & Shortest, $N=200$ & Longest, $N=198$ \\
\hline 112 G $>A(G 38 S)$ & $81(40.5 \%)$ & $74(37.4 \%)$ \\
GG & $93(46.5 \%)$ & $97(49.0 \%)$ \\
GA & $26(13.0 \%)$ & $27(13.6 \%)$ \\
AA & $0.637 / 0.363$ & $0.619 / 0.381$ \\
Allele frequencies & $1.15[0.77-1.72], P=0.50$ \\
OR [95\% CI] & & \\
253 G $>A(D 85 N)$ & $197(98.5 \%)$ & $186(93.9 \%)$ \\
GG & $3(1.5 \%)$ & $0(0.0 \%)$ \\
GA & $0(0.0 \%)$ & $0.970 / 0.030 * * *$ \\
AA & $0.992 / 0.008$ & \\
Allele frequencies & $4.21[1.17-15.16], P=0.028$ \\
OR [95\% Cl]
\end{tabular}

Nucleotide numbering starts from the ATG start codon (Genbank accession M26685).

${ }^{a}$ Carriers of the minor allele opposed to homozygotes for the frequent allele; ${ }^{* *} P=0.016$.

in the shortest QTc group (0.008 in the shortest QTc vs 0.030 in the longest QTc group, $P=0.016)$. No homozygote $253 \mathrm{~A} / \mathrm{A}$ was identified in this study population. The OR [95\% CI] for longest QTc associated with carriage of minor A allele was 4.21 [1.17-15.16], $P=0.028$ ) (Table 3). Frequencies of the four possible haplotypes were not estimated owing to the low frequency of the 253 A allele.

\section{KCNH2 $2690 \mathrm{~A}>\mathrm{C}$ polymorphism}

The KCNH2 2690 A > C SNP, leading to the K897T aminoacid change, had previously been reported in Finnish (frequency of $\left.0.16^{21,32}\right)$, German $\left(\approx 0.24^{22}\right)$, American $\left(0.14^{15}\right)$ and Japanese $\left(0.02^{33}\right)$ populations. The minor allele frequency $\mathrm{KCNH} 22690 \mathrm{C}$ in the French population was 0.27 , close to that of the German population.

Genotype frequencies were in the Hardy-Weinberg equilibrium in the two groups.

The minor allele $2690 \mathrm{C}$ was significantly more frequent in the group with the shortest QTc interval $(0.31$ in the shortest QTc vs 0.22 in the longest QTc group, $P=0.0065$ ) and was associated with a lower risk of QTc interval prolongation $(\mathrm{OR}=0.64$ [0.46-0.88], $P=0.0055)$ (Table 4). This effect was seen in males as well as females $(\mathrm{OR}=0.70$ $[0.45-1.08])$ for males, $\mathrm{OR}=0.57[0.36-0.91]$ for females, $P=0.50$.

\section{SCN5A polymorphisms}

In this study, four SCN5A SNPs were analyzed: $1141-3 \mathrm{C}>\mathrm{A}$ in intron 9, $1673 \mathrm{~A}>\mathrm{G}$ in exon 12 , leading to the aminoacid change H558R, $5457 \mathrm{C}>\mathrm{T}$ in exon 28 leading to the 
Table 4 Frequency of $K C N H 2$ gene polymorphism in the shortest and longest QTc groups and odds ratio $(95 \% \mathrm{Cl})$ for longest QTc associated with genotype

\begin{tabular}{lcc}
\hline & \multicolumn{2}{c}{ QTC } \\
Polymorphism & Shortest $N=200$ & Longest $N=198$ \\
\hline 2690 A $>C($ K897T) & & \\
AA & $99(49.5 \%)$ & $119(60.1 \%)$ \\
AC & $77(38.5 \%)$ & $71(35.9 \%)$ \\
CC & $24(12.0 \%)$ & $8(4.0 \%)$ \\
Allele frequencies & $0.687 / 0.313$ & $0.780 / 0.220^{* * *}$ \\
${\text { OR }[95 \% ~ C l]^{a}}^{\text {a }}$ & $0.64[0.46-0.88], P=0.0055$ \\
\hline
\end{tabular}

Nucleotide numbering starts from the ATG start codon (Genbank accession U04270).

${ }^{a}$ Carriers of the minor allele opposed to homozygotes for the frequent allele; ${ }^{* *} P=0.0065$.

synonymous polymorphism D1819D, and -92 C > A in the core promoter of the gene.

The minor allele frequencies were 0.20 for 1141-3 A, 0.24 for $1673 \mathrm{G}, 0.31$ for $5457 \mathrm{~T}$, and 0.003 (two out of 780 alleles) for $-92 \mathrm{~A}$. This latest SNP was less represented in our population than in the previous sample of 71 subjects of mixed ethnicity $(N=71,4.2 \%) .{ }^{34}$ Owing to its low frequency, it was not studied further.

The three frequent SNPs were in the Hardy-Weinberg equilibrium in the two groups.

The 1141-3 $\mathrm{C}>\mathrm{A}$ and $1673 \mathrm{~A}>\mathrm{G}$ SNPs were in strong association, with only $8.3 \%$ of recombinant subjects. These two polymorphisms were in weak LD with the $5457 \mathrm{C}>\mathrm{T}$ polymorphism (Table $\mathrm{C}$, web supplement). The minor alleles 1141-3 A and $1673 \mathrm{G}$ were more frequent in the group with the longest QTc interval, with an OR [95\% CI] of 1.66 [1.182.35], $P=0.0039$ associated with carriage of allele $1141-3 \mathrm{~A}$ and 1.5 [1.1-2.1], $P=0.01$ associated with carriage of allele $1673 \mathrm{G}$ (Table 5). Conversely, the minor allele $5457 \mathrm{~T}$ was more frequent in the group with the shortest QTc interval and associated with a lower risk of QTc interval prolongation $(\mathrm{OR}=0.65$ [0.48-0.89], $P=0.0063)$ (Table 5).

A haplotype analysis combining the 1141-3 C $>$ A SNP and the $5457 \mathrm{C}>\mathrm{T}$ polymorphisms was performed. The $1673 \mathrm{~A}>\mathrm{G}$ polymorphism was not included in the haplotype analysis because of its high concordance with the 1141-3 C>A. There was a globally significant difference in haplotype distribution between the two groups $(P=0.002)$ (Table 6$)$. We examined whether the effect of each polymorphism had an independent effect on risk by testing the interaction between the two alleles, but this did not reach significance $(P=0.65)$, indicating that the two polymorphisms acted independently from each other.

\section{Interaction between polymorphisms among the four genes}

Potential interactions between polymorphisms of the different genes were explored in a systematic way. An
Table 5 Frequency of SCN5A gene polymorphisms in the shortest and longest QTc groups and odds ratio $(95 \% \mathrm{Cl})$ for longest QTc associated with genotype

\begin{tabular}{|c|c|c|}
\hline \multirow[b]{2}{*}{ Polymorphism } & \multicolumn{2}{|c|}{ QTC } \\
\hline & Shortest $N=200$ & Longest $N=198$ \\
\hline \multicolumn{3}{|l|}{$1141-3 C>A$} \\
\hline $\mathrm{CC}$ & $139(69.5 \%)$ & $117(59.1 \%)$ \\
\hline CA & $57(28.5 \%)$ & $64(32.3 \%)$ \\
\hline AA & $4(2.0 \%)$ & $17(8.6 \%)$ \\
\hline Allele frequencies & $0.837 / 0.163$ & $0.753 / 0.247^{\star}$ \\
\hline OR $[95 \% \mathrm{Cl}]^{\mathrm{a}}$ & \multicolumn{2}{|c|}{$1.66[1.18-2.35], P=0.0039$} \\
\hline \multicolumn{3}{|c|}{$1673 A>G(H 558 R)$} \\
\hline $\mathrm{AA}$ & $126(63.0 \%)$ & $106(53.5 \%)$ \\
\hline$A G$ & $66(33.0 \%)$ & $71(35.9 \%)$ \\
\hline GG & $8(4.0 \%)$ & $21(10.6 \%)$ \\
\hline Allele frequencies & $0.795 / 0.205$ & $0.715 / 0.285^{* *}$ \\
\hline OR $[95 \% \mathrm{Cl}]^{\mathrm{a}}$ & \multicolumn{2}{|c|}{$1.52[1.11-2.10], P=0.010$} \\
\hline \multicolumn{3}{|c|}{$5457 C>T(D 1819 D)$} \\
\hline $\mathrm{CC}$ & $77(38.5 \%)$ & $109(55.0 \%)$ \\
\hline CT & $103(51.5 \%)$ & 71 (35.9\%) \\
\hline$\pi$ & $20(10.0 \%)$ & $18(9.1 \%)$ \\
\hline Allele frequencies & $0.642 / 0.358$ & $0.730 / 0.270^{* * *}$ \\
\hline OR $[95 \% \mathrm{CI}]^{\mathrm{a}}$ & \multicolumn{2}{|c|}{$0.65[0.48-0.89], P=0.0063$} \\
\hline
\end{tabular}

Nucleotide numbering starts from the ATG start codon (Genbank accession NM000335).

${ }^{a}$ Carriers of the minor allele opposed to homozygotes for the frequent allele; ${ }^{*} P=0.0057,{ }^{* *} P=0.0210,{ }^{* *} P=0.0032$.

Table 6 Comparison of the main haplotype frequencies of the SCN5A gene in the shortest and longest QTC groups

\begin{tabular}{lcccc}
\hline \multicolumn{4}{c}{ Haplotypes } & \multicolumn{2}{c}{ Frequency } \\
& & & \\
$1141-3 C>A$ & 5457 C $>T$ & Shortest & Longest & P-value \\
\hline C & C & 0.515 & 0.528 & Reference \\
C & T & 0.323 & 0.224 & 0.020 \\
A & C & 0.128 & 0.202 & 0.087 \\
A & T & 0.034 & 0.046 & 0.580 \\
\hline
\end{tabular}

Global difference in haplotype frequencies between the shortest and longest QTc groups: $P=0.002$.

interaction was detected between the KCNH2 $2690 \mathrm{~A}>\mathrm{C}$ SNP and the KCNQ1 $2031+932 \mathrm{~A}>\mathrm{G}$ polymorphism. Actually, the effect of the KCNH2 $2690 \mathrm{C}$ allele previously observed appeared to be confined to homozygotes for the major KCNQ1 2031+932 A allele $(\mathrm{OR}=0.33$ [0.18-0.60], $P=0.0003)$, whereas the effect was not significant in carriers of the KCNQ1 $2031+932 \mathrm{G}$ allele $(\mathrm{OR}=1.18$ $[0.67-2.05]$ ) (test of homogeneity of ORs, $P=0.004$ ). 


\section{Discussion}

While gender and age influence QT duration, a genetic determination of the QT length has been suggested. ${ }^{7}$ Several studies have focused on SNPs located in genes responsible for the LQTS as potential determinants of cardiac repolarization duration. Indeed, the cardiac AP is orchestrated by potassium and sodium ion channel subunits encoded by the KCNQ1 (LQT1), KCNE1 (LQT5), KCNH2 (LQT2), KCNE2 (LQT6) and SCN5A (LQT3) genes, in which rare mutations lead to QTc prolongation associated with ventricular arrhythmias. The first SNPs found associated with the QTc length in healthy subjects were $2690 \mathrm{~A}>\mathrm{C}(\mathrm{K} 897 \mathrm{~T})$ of $K C N H 2^{21,22,32}$ and, more recently, SNPs in KCNQ1, KCNE1, KCNE2 and SCN5A. ${ }^{23,35}$

While these studies determined the impact of SNPs on QT length as a quantitative trait, we adopted an original approach by opposing two contrasted groups of healthy untreated subjects: 200 subjects presenting the shortest and 198 subjects presenting the longest QTc interval length, selected from a cohort of 2008 healthy subjects. We then compared the allele, genotype and haplotype frequencies of $10 K C N Q 1$, two KCNE1, four SCN5A and one $K C N H 2$ SNPs between the two groups and searched for potential interactions between them.

\section{$K C N Q 1$ and $K C N E 1$ polymorphisms}

We screened the entire coding sequence, exon/intron boundaries and the $3^{\prime} \mathrm{UTR}$ region of the KCNQ1 gene and identified six new rare SNPs $(<0.10)(459 \mathrm{G}>\mathrm{T}(\mathrm{T} 153 \mathrm{~T})$, $477+20 \mathrm{~A}>\mathrm{G}, 918+13 \mathrm{C}>\mathrm{T}, 984 \mathrm{C}>\mathrm{T}(\mathrm{I} 328 \mathrm{I}), 1514+7$ $\mathrm{G}>\mathrm{T}$ and $1514+14 \mathrm{G}>\mathrm{T})$, and two more frequent ones $(>0.10)(477+80$ insGG, $2031+479 \mathrm{G}>\mathrm{A})$.

Busjahn et $\mathrm{al}^{7}$ initially suggested that the LQT1 locus, containing KCNQ1, may represent a quantitative trait locus (QTL) for the QTc phenotype in the normal population. However, in our study, no KCNQ1 SNPs, alone or in combination, demonstrated an association with the QTC length. In a recent study, Aydin and $a l^{23}$ also failed to identify KCNQ1 SNPs associated with QTc length in the normal monozygotic and dizygotic twins previously studied by Busjahn. The discrepancy between results from linkage and association studies suggests that a different gene in the vicinity of KCNQ1 might be at the origin of the linkage previously detected in the region. Another explanation might be that there exists in KCNQ1 an undetected functional SNP not in complete LD with the SNPs genotyped in the present study as well as in Aydin's report. $^{23}$ Besides, in a recent report analyzing 81 SNPs spreading over the entire KCNQ1 gene, several haplotype blocks were identified in weak LD one with each other, and a rare $\mathrm{G}$ allele (rs757092 $\mathrm{A}>\mathrm{G}$ ) in a high LD haplotype block in intron 1 was associated with a QTc prolongation in the study population. ${ }^{35}$ The $477+80$ insGG polymorphism is located $50 \mathrm{~kb}$ downstream from the rs757092 A $>$ G SNP in the genomic sequence of KCNQ1. They may be in weak
LD in our population and would explain why we failed to detect any KCNQ1 SNP effect on the QTc length.

We also hypothesized that allelic variants in the regulatory subunit of the $I_{\mathrm{Ks}}$ channel, minK encoded by $K C N E 1$, could influence the channel function, and as a consequence, the length of the QTc interval. We studied two known nonsynonymous polymorphisms, G38S ${ }^{23,36}$ and D85N. ${ }^{19,23,37}$ Although the G38 allele was shown to be associated with atrial fibrillation, ${ }^{36}$ none of the G38S alleles was associated with the QTc length in our French population of healthy subjects. In contrast, the rare N85 allele was four times more frequent in the group with the longest QTc interval than in the group with the shortest QTc.

Wei et $a l^{19}$ described the N85 allele as a risk factor of drug-induced LQT syndrome. In this study, no variation in $I_{\mathrm{Ks}}$ current amplitude was observed when N85-minK was coexpressed with wild-type (WT) KvLQT1 in CHO cells, the channels activated more slowly and deactivated to a greater extent after a long diastolic pause, a latent defect that may be unmasked by drug block and render individuals susceptible to acquired LQTS.

Recently, the N85 variant was reported in some LQTS patients presenting longer QTc intervals and a higher incidence of cardiac arrhythmia compared to family members carrying only a LQT syndrome mutation. In this study, a marked reduction of $I_{\mathrm{Ks}}$ current was observed when the N85-minK variant was coexpressed with the WT KvLQT1 channel in Xenopus oocytes. ${ }^{38}$

Whatever the discrepancy about the KvLQT1/N85-minK channel properties expressed in heterologous expression systems, there is evidence that the KCNE1 N85 allele modifies the $I_{\mathrm{Ks}}$ channel function leading to a prolongation of the QTc interval length, which means that D85N would be a 'functional' polymorphism. Our association study is in accordance with these studies since 6\% (12/198) of healthy subjects with a QTc interval in the upper limit (394-433 ms) were carriers of the N85 allele compared to $1.5 \%(3 / 200)$ of healthy subjects with shorter QTc interval ( $<365 \mathrm{~ms})$.

Recent association studies reported the rare allele IVS2$128 \mathrm{~A}$ and rs727957 $\mathrm{T}$ associated with the prolongation of the QTc length in healthy Caucasian subjects. ${ }^{23,35}$ The former is located in intron 2 and the latter in a haplotype block ending $20 \mathrm{~kb}$ upstream of the KCNE1 gene. The functional nature of these SNPs is undetermined but these data indicate that the KCNE1 gene may act as a QTL for the cardiac ventricular repolarization in healthy subjects. Thus, these SNPs represent good candidates to explore the penetrance variability in LQT syndrome patients.

\section{The KCNH2 K897T polymorphism}

We found that the $2690 \mathrm{C}$ allele, leading to a threonine residue at position 897 of the HERG protein, was more prevalent in the group with the shortest QTc interval. This 
result is in accordance with previous association studies. $^{22,35}$ Bezzina et $a l^{22}$ showed that female $2690 \mathrm{C} / \mathrm{C}$ homozygotes had shorter QTc intervals in comparison to female heterozygotes and 2690 A/A homozygotes. Moreover, they showed by in vitro studies that HERG-T897 channels hastened cardiac repolarization compared to HERG-K897 channels. By contrast, an earlier association study in a Finnish population showed opposite results: female heterozygotes or $2690 \mathrm{C} / \mathrm{C}$ homozygotes had longer QTc intervals than females 2690 A/A homozygotes. ${ }^{32}$ This discrepancy may reflect either the occurrence of additional population-specific functional polymorphisms, influencing the effect of the K897T polymorphism, or the limitations of association studies.

Our results not only confirmed a hastened cardiac repolarization in both male and female carriers of the $2690 \mathrm{C}$ allele but also suggested that this effect may be dependent on a KCNQ1 polymorphism located in the 3'UTR part of the gene $(2031+932 \mathrm{~A}>\mathrm{G})$.

Interestingly, $I_{\mathrm{Kr}}$, underlined by the HERG channels, and $I_{\mathrm{Ks}}$, underlined by KvLQT1/minK channels, were shown to interact both at a functional and a physical level. Indeed, when $I_{\mathrm{Kr}}$ is reduced, the Ap is prolonged, causing $I_{\mathrm{Ks}}$ activation to increase so as to prevent excessive repolarization delays, ${ }^{39,40}$ and KvLQT1 was found to associate physically with HERG in both $\mathrm{CHO}$ cells and native cardiomyocytes, and to increase membrane localization of HERG in CHO cells. ${ }^{41}$

The only KCNQ1 allele in interaction with the HERGT897 allele is located in the $3^{\prime}$ UTR part of the gene. This KCNQ1 2031+932 A allele, or a yet unidentified polymorphism LD with it, may lead to more stable transcripts, or to a better subcellular targeting as previously shown for other genes. ${ }^{42-44}$ Even if a direct effect on QTc length was not detectable, the KCNQ1 2031+932 A may potentiate the $I_{\mathrm{Kr}}$ current displayed by the HERG-T897 channels. $^{22}$

\section{SCN5A polymorphisms}

We studied four SCN5A SNPs which have been previously reported: -92 $\mathrm{C}>\mathrm{A}^{34} 1141-3 \mathrm{C}>\mathrm{A},{ }^{23} 1673 \mathrm{~A}>\mathrm{G}$ (H558R), ${ }^{15,33} 5457 \mathrm{C}>\mathrm{T}$ (D1819D). ${ }^{33}$ Almost completely concordant, the 1141-3 A and $1673 \mathrm{G}$ minor alleles were more frequent in the group with the longest QTc interval, whereas the $5457 \mathrm{~T}$ minor allele was more frequent in the group with the shortest QTc length. The effects of the 1141-3 C>A (or the $1673 \mathrm{~A}>\mathrm{G}$ ) and the $5457 \mathrm{C}>\mathrm{T}$ SNPs were independent, as shown by the haplotype analysis.

The association of the $1673 \mathrm{~A}>\mathrm{G}$ SNP, or H558R, with QT length confirms the result recently published by Aydin et al. $^{23}$ This polymorphism is located in the $\mathrm{Na}^{+}$channel I-II interdomain cytoplasmic linker, and two studies have suggested that it could modulate the effect of arrhythmiacausing SCN5A mutations. ${ }^{16,45}$ However, no difference in $\mathrm{Na}^{+}$channel activation and inactivation has been observed between the hH1-H558 and the hH1-R558 clones. ${ }^{16}$
It is not possible from our results to disentangle the effect of the H558R polymorphism from that of the 1141-3 C > A SNP because of their tight LD. This latter SNP is located in the acceptor splice site in intron 9 and might affect the splicing. The observed effect may also be due to another unknown polymorphism in LD with these two SNPs.

The minor allele of the $5457 \mathrm{C}>\mathrm{T}$ SNP, located in the last exon of the gene (exon 28) and leading to the synonymous D1819D polymorphism, was associated with the shortest QTc length. Interestingly, Aydin et al ${ }^{23}$ described a SNP located in intron 24 of $S C N 5 A$ (IVS2 $4+116 \mathrm{G}>\mathrm{A}$ ) with the minor allele associated with a shorter QTc. The functional nature of these variants on the sodium channel activity or expression remains elusive at this point. Indeed, gain of function mutations in SCN5A were associated with a QTC prolongation in LQTS patients, while loss of function mutations did not produce a QTc shortening in Brugada patients.

One potential limitation of our study was that it was restricted to healthy untreated subjects. We excluded patients taking medications susceptible to prolong the QT interval (antiarrhythmics, neuroleptics, antihistaminics, antihypertensive treatments), as well as subjects with cardiovascular diseases or diabetes. For this reason, extrapolation of our results to the general population might be questionable. Replication of the present results in an independent population would greatly strengthen our findings.

The findings of our study are important for a better understanding of the risk of arrhythmias and sudden death in healthy subjects as well as in patients with cardiovascular diseases. Indeed, a prolonged baseline QT interval was shown to predispose patients with coronary artery disease to sudden death ${ }^{46}$ or myocardial infarction ${ }^{47,48}$ whereas a short baseline QT interval was associated with reduced mortality in dofetilide-treated patients with moderate to severe heart failure and reduced left ventricular systolic function. ${ }^{49}$ Although rare, the SQTS where patients present a drastic decrease of the QTC interval is also linked to life-threatening arrhythmias and sudden death. ${ }^{12}$ So KCNH2 2690A >C (K897T) and SCN5A 5457 $\mathrm{C}>\mathrm{T}$ SNPs would be expected to be protective factors, while KCNE1 $253 \mathrm{G}>\mathrm{A}$ (D85N), SCN5A 1141-3 C>A and $1673 \mathrm{~A}>\mathrm{G}$ (H558R) would be risk factors for QT prolongation and onset of arrhythmias in patients with LQT syndrome or with other cardiovascular diseases; the contrary would be expected in patients with a SQTS.

In conclusion, our results suggest that genetic polymorphisms located in the KCNQ1, KCNE1, KCNH2 and SCN5A genes might, independently or in interaction, influence the QTc length in healthy Caucasian subjects. These variants might also modulate the effects of ion channel mutations leading to arrhythmias such as LQT and Brugada syndromes and contribute to the phenotypic variability observed in these disorders. 


\section{Acknowledgements}

This work was supported by the Inserm, Fondation de France, and Fondation Leducq. We thank Dr Bernard Hainque and Dr Véronique Fressart for their continuous collaboration and their critical review of the manuscript, Dr Fabrice Extramania and Dr Pierre Maison-Blanche for critical discussion about population selection and QTc interval evaluation, and Françoise Simon for her technical help in identifying polymorphisms. The design of hybridization probes for the Fluorescence Resonance Energy Transfer assays was from Olfert Landt, TIB MOLBIOL.

\section{References}

1 Merri M, Benhorin J, Alberti M, Locati E, Moss AJ: Electrocardiographic quantitation of ventricular repolarization. Circulation 1989; 80: 1301-1308.

2 Rautaharju PM, Zhou SH, Wong S et al: Sex differences in the evolution of electrocardiographic QT interval with age. Can $J$ Cardiol 1992; 8: 690-695.

3 Bazett $\mathrm{H}$ : An analysis of the time relations of electrocardiograms. Heart 1920; 7: 353-367.

4 Burke JH, Goldberger JJ, Ehlert FA, Kruse JT, Parker MA, Kadish $\mathrm{AH}$ : Gender differences in heart rate before and after autonomic blockade: evidence against an intrinsic gender effect. Am J Med 1996; 100: 537-543.

5 Batchvarov VN, Ghuran A, Smetana P et al: QT-RR relationship in healthy subjects exhibits substantial intersubject variability and high intrasubject stability. Am J Physiol Heart Circ Physiol 2002; 282: $\mathrm{H} 2356-\mathrm{H} 2363$.

6 Hanson B, Tuna N, Bouchard T et al: Genetic factors in the electrocardiogram and heart rate of twins reared apart and together. Am J Cardiol 1989; 63: 606-609.

7 Busjahn A, Knoblausch H, Faulhaber H-D et al: QT interval is linked to 2 long-QT syndrome loci in normal subjects. Circulation 1999; 99: 3161-3164.

8 Barhanin J, Lesage F, Guillemare E, Fink M, Lazdunski M, Romey G: KvLQT1 and IsK (minK) proteins associate to form the Iks cardiac potassium current. Nature 1996; 384: 78-80.

9 Sanguinetti MC, Curran ME, Zou A et al: Coassembly of KVLQT1 and $\operatorname{minK}(\mathrm{IsK})$ proteins to form cardiac IKs potassium channel. Nature 1996; 384: 80-83.

10 Sanguinetti MC, Jiang C, Curran ME, Keating MT: A mechanistic link between an inherited and an acquired cardiac arrhythmia: HERG encodes the Ikr potassium channel. Cell 1995; 81: 299-307.

11 Abbott GW, Sesti F, Splawski I et al: MIRP1 forms IKr potassium channels with HERG and is associated with cardiac arrhythmia. Cell 1999; 97: 175-187.

12 Brugada R, Hong K, Dumaine R et al: Sudden death associated with short-QT syndrome linked to mutations in HERG. Circulation 2004; 109: 30-35.

13 Bellocq C, van Ginneken AC, Bezzina CR et al: Mutation in the KCNQ1 gene leading to the short QT-interval syndrome. Circulation 2004; 109: 2394-2397.

14 Priori SG, Napolitano C, Schwartz PJ: Low penetrance in the longQT syndrome Clinical impact. Circulation 1999; 99: 529-533.

15 Yang P, Kanki H, Drolet B et al: Allelic variants in long-QT disease genes in patients with drug-associated torsades de pointes. Circulation 2002; 105: 1943-1948.

16 Viswanathan PC, Benson DW, Balser JR: A common SCN5A polymorphism modulates the biophysical effects of an SCN5A mutation. J Clin Invest 2003; 111: 341-346.

17 Groenewegen WA, Firouzi M, Bezzina CR et al: A cardiac sodium channel mutation cosegregates with a rare connexin 40 genotype in familial atrial standstill. Circ Res 2003; 92: 14-22.

18 Sesti F, Abbott GW, Wei J et al: A common polymorphism associated with antibiotic-induced cardiac arrhythmia. Proc Natl Acad Sci USA 2000; 97: 10613-10618.
19 Wei J, C-H YI, R TA et al: KCNE1 polymorphism confers risk of drug-induced long QT syndrome by altering kinetic properties of $I_{\mathrm{ks}}$ potassium channels. Circulation 1999; (Suppl I): I-495 (Abstract)

20 Splawski I, Timothy KW, Tateyama M et al: Variant of SCN5A sodium channel implicated in risk of cardiac arrhythmia. Science 2002; 297: 1333-1336.

21 Laitinen P, Fodstad H, Piippo K et al: Survey of the coding region of the HERG gene in long QT syndrome reveals six novel mutations and an amino acid polymorphism with possible phenotypic effects. Hum Mutat 2000; 15: 580-581.

22 Bezzina CR, Verkerk AO, Busjahn A et al: A common polymorphism in KCNH2 (HERG) hastens cardiac repolarization. Cardiovasc Res 2003; 59: 27-36.

23 Aydin A, Bahring S, Dahm S et al: Single nucleotide polymorphism map of five long-QT genes. J Mol Med 2005; 83: 159-165.

24 Balkau B, Eschwege E, Tichet J, Marre M, group DESIR: Proposed criteria for the diagnosis of diabetes: evidence from a French epidemiological study (D.E.S.I.R.). Diabet Metab 1997; 23: $428-434$.

25 Gallois Y, Vol S, Caces E, Balkau B: Distribution of fasting serum insulin measured by enzyme immunoassay in an unselected population of 4032 individuals. Reference values according to age and sex. D.E.S.I.R. Study Group. Données Epidémiologiques sur le Syndrome d'Insulino-Resistance. Diabet Metab 1996; 22: 427-431.

26 Puddu PE, Jouve R, Mariotti S et al: Evaluation of 10 QT prediction formulas in 881 middle-aged men from the seven countries study: emphasis on the cubic root Fridericia's equation. J Electrocardiol 1988; 21: 219-229.

27 Gouas L, Bellocq C, Berthet M et al: New KCNQ1 mutations leading to haploinsufficiency in a general population; defective trafficking of a KvLOT1 mutant. Cardiovasc Res 2004; 63: 60-68.

28 Neyroud N, Richard P, Vignier $\mathrm{N}$ et al: Genomic organization of the KCNQ1 potassium channel gene and identification of C-terminal mutations in the long QT syndrome. Circ Res 1999; 84: $290-297$.

29 Tiret L, Amouyel P, Rakotovao R, Cambien F, Ducimetiere P: Testing for association between disease and linked marker loci: a log-linear-model analysis. Am J Hum Genet 1991; 48: 926-934.

30 Tregouet DA, Escolano S, Tiret L, Mallet A, Golmard JL: A new algorithm for haplotype-based association analysis: the Stochastic-EM algorithm. Ann Hum Genet 2004; 68: 165-177.

31 Tahri-Daizadeh N, Tregouet DA, Nicaud V, Manuel N, Cambien F, Tiret L: Automated detection of informative combined effects in genetic association studies of complex traits. Genome Res 2003; 13: $1952-1960$.

32 Pietila E, Fodstad H, Niskasaari E et al: Association between HERG K897T polymorphism and QT interval in middle- aged Finnish women. J Am Coll Cardiol 2002; 40: 511-514.

33 Iwasa H, Itoh T, Nagai R, Nakamura Y, Tanaka T: Twenty single nucleotide polymorphisms (SNPs) and their allelic frequencies in four genes that are responsible for familial long QT syndrome in the Japanese population. J Hum Genet 2000; 45: 182-183.

34 Yang P, Kupershmidt S, Roden DM: Cloning and initial characterization of the human cardiac sodium channel (SCN5A) promoter. Cardiovasc Res 2004; 61: 56-65.

35 Pfeufer A, Jalilzadeh S, Perz S et al: Common variants in myocardial ion channel genes modify the QT interval in the general population: results from the KORA study. Circ Res 2005; 96: 693-701.

36 Lai LP, Su MJ, Yeh HM et al: Association of the human minK gene $38 \mathrm{G}$ allele with atrial fibrillation: evidence of possible genetic control on the pathogenesis of atrial fibrillation. Am Heart J 2002; 144: $485-490$.

37 Tesson F, Donger C, Denjoy I et al: Exclusion of KCNE1 (IsK) as a candidate gene for Jervell and Lange-Nielsen syndrome. $J$ Mol Cell Cardiol 1996; 28: 2051-2055.

38 Westenskow P, Splawski I, Timothy KW, Keating MT, Sanguinetti MC: Compound mutations: a common cause of severe long-QT syndrome. Circulation 2004; 109: 1834-1841. 
39 Varro A, Balati B, Iost $\mathrm{N}$ et al: The role of the delayed rectifier component IKs in dog ventricular muscle and Purkinje fibre repolarization. J Physiol 2000; 523 (Part 1): 67-81.

40 Biliczki P, Virag L, Iost N, Papp JG, Varro A: Interaction of different potassium channels in cardiac repolarization in dog ventricular preparations: role of repolarization reserve. $\mathrm{Br} J$ Pharmacol 2002; 137: 361-368.

41 Ehrlich JR, Pourrier M, Weerapura M et al: KvLQT1 modulates the distribution and biophysical properties of HERG. A novel alphasubunit interaction between delayed rectifier currents. $J$ Biol Chem 2004; 279: 1233-1241.

42 Subramaniam K, Chen K, Joseph K, Raymond JR, Tholanikunnel BG: The 3'-untranslated region of the beta2-adrenergic receptor mRNA regulates receptor synthesis. J Biol Chem 2004; 279: 27108-27115.

43 Pontrelli L, Sidiropoulos KG, Adeli K: Translational control of apolipoprotein B mRNA: regulation via cis elements in the $5^{\prime}$ and $3^{\prime}$ untranslated regions. Biochemistry 2004; 43: $6734-6744$.
44 Rousseau P, Le Discorde M, Mouillot G, Marcou C, Carosella ED, Moreau P: The $14 \mathrm{bp}$ deletion-insertion polymorphism in the $3^{\prime}$ UT region of the HLA-G gene influences HLA-G mRNA stability. Hum Immunol 2003; 64: 1005-1010.

45 Ye B, Valdivia CR, Ackerman MJ, Makielski JC: A common human SCN5A polymorphism modifies expression of an arrhythmia causing mutation. Physiol Genomics 2003; 12: 187-193.

46 Puddu PE, Bourassa MG: Prediction of sudden death from QTc interval prolongation in patients with chronic ischemic heart disease. J Electrocardiol 1986; 19: 203-211.

47 Schwartz PJ, Wolf S: QT interval prolongation as predictor of sudden death in patients with myocardial infarction. Circulation 1978; 57: 1074-1077.

48 Ahnve S: QT interval prolongation in acute myocardial infarction. Eur Heart J 1985; 6 (Suppl D): 85-95.

49 Brendorp B, Elming H, Jun L et al: Qtc interval as a guide to select those patients with congestive heart failure and reduced left ventricular systolic function who will benefit from antiarrhythmic treatment with dofetilide. Circulation 2001; 103: 1422-1427.

Supplementary Information accompanies the paper on European Journal of Human Genetics website (http://www.nature.com/ejhg) 